University of Nebraska - Lincoln

DigitalCommons@University of Nebraska - Lincoln

Agronomy \& Horticulture -- Faculty Publications

Agronomy and Horticulture Department

$4-2020$

\title{
A global perspective on sustainable intensification research
}

\author{
Kenneth Cassman \\ University of Nebraska - Lincoln, kcassman1@unl.edu \\ Patricio Grassini \\ University of Nebraska - Lincoln, pgrassini2@unl.edu
}

Follow this and additional works at: https://digitalcommons.unl.edu/agronomyfacpub

Part of the Agricultural Science Commons, Agriculture Commons, Agronomy and Crop Sciences Commons, Botany Commons, Horticulture Commons, Other Plant Sciences Commons, and the Plant Biology Commons

Cassman, Kenneth and Grassini, Patricio, "A global perspective on sustainable intensification research" (2020). Agronomy \& Horticulture -- Faculty Publications. 1344.

https://digitalcommons.unl.edu/agronomyfacpub/1344

This Article is brought to you for free and open access by the Agronomy and Horticulture Department at DigitalCommons@University of Nebraska - Lincoln. It has been accepted for inclusion in Agronomy \& Horticulture -Faculty Publications by an authorized administrator of DigitalCommons@University of Nebraska - Lincoln. 


\title{
A global perspective on sustainable intensification research
}

\author{
Kenneth G. Cassman and Patricio Grassini \\ Department of Agronomy and Horticulture, \\ University of Nebraska-Lincoln, Lincoln, NE, USA \\ Corresponding author - K.G. Cassman, email kcassman1@unl.edu
}

\begin{abstract}
Despite general agreement that meeting food demand without further loss of natural ecosystems requires sustainable intensification, there is little dialogue about the research agenda needed to achieve it. To that end, we evaluate current trajectories towards sustainable intensification, review published research on the topic, identify missing links, and propose a prioritization framework to fill gaps. Although progress towards sustainable intensification is behind schedule, we are optimistic that current trends can get back on course assuming a well-prioritized and adequately funded research portfolio and appropriate policies and institutions to support it.
\end{abstract}

In the broadest sense, sustainable intensification (SI) seeks to increase crop and livestock yields and associated economic returns per unit time and land without negative impacts on soil and water resources or the integrity of associated non-agricultural ecosystems ${ }^{1}$. Success in implementing an SI approach is best quantified by metrics

Published in Nature Sustainability 3 (April 2020), pp 262-268.

DOI: $10.1038 / \mathrm{s} 41893-020-0507-8$

Copyright (C) Springer Nature Limited 2020. Used by permission.

Submitted 27 April 2019; accepted 3 March 2020; published 16 April 2020. 
that measure system outputs (again, broad sense) in terms of: (1) yield; (2) input requirements to achieve that yield; (3) impact on soil quality defined as the capacity to support crop yields and inputuse efficiencies ${ }^{2}$; and (4) impact on natural resources and ecosystems affected by the production system. Hence, in addition to yield, SI must be evaluated by efficiency metrics such as yield per unit input of energy, water and nutrients rather than by the source or type of inputs (for example, organic or conventional, genetically modified organism (GMO) or non-GMO), and by impacts on a broad array of ecosystem services with particular concern for water quality and biodiversity ${ }^{3}$.

The potential to achieve SI and the degree to which it is achieved can be considered from a local field or farm scale, to regional, national and global scales. At a local level, SI of small-scale subsistence farms might include judicious use of fertilizer and greater diversification with high-value vegetable crops, or addition of fishponds and livestock that utilize by-products from crop production and allow return of animal manures to help maintain soil fertility. On largescale mechanized farms, intensification typically involves manipulating crop and soil management practices to eke out further efficiencies in capture of resources and conversion to yield. Examples include use of shorter-maturing crop varieties to allow production of an additional crop each year on the same field, improved nutrient management practices that better synchronize nutrient supply with crop demand during the growing season without excess or deficiency, conservation tillage that increases infiltration of rainfall and reduced runoff, and cover crops to recover fertilizer nutrients not taken up by the cash crop and to protect soil from erosion, to name a few. In all cases, the capacity of soil to provide water and nutrients to support crop growth must be maintained or enhanced to ensure sustainability in terms of soil quality.

The call for 'sustainable intensification' originally focused on the need to move beyond the seed, fertilizer and pesticide technologies that support modern, high-yield conventional agriculture, towards more 'restorative' production systems that rely less on external inputs and more on leveraging internal resources and ecological processes to supply nutrients and control pests ${ }^{4}$. Since then, justification for SI, and closely related 'ecological intensification', has expanded to address national and global concerns about agriculture's negative 
impact on environmental quality and natural resources on one hand, and need to achieve substantial increases in crop yields on existing farmland to avoid further loss of natural habitat on the other ${ }^{1-3}$. Of particular concern is conversion of rainforests, grassland savannahs and wetlands to crop production and the associated loss of biodiversity and soil carbon stocks, the latter contributing considerably to anthropogenic greenhouse gas (GHG) emissions. And while SI is necessary to address these challenges, it is not sufficient because success in conserving natural habitat also requires good governance, appropriate legal frameworks for land tenure, and international agreements to ensure that progress towards SI on existing farmland achieves desired environmental outcomes ${ }^{5}$.

Evaluating the potential of existing agricultural systems to undergo SI at national and global scales provides insight about land, water and energy requirements to ensure adequate food supply while also addressing concerns about climate change and biodiversity. A global lens helps illuminate broad trends and drivers of future food supply and commodity prices in international markets, which in turn provides critical input to national research and development (R\&D) priorities because most countries currently rely on imports to meet food demand. Effective priority setting at a national scale identifies the crops, cropping systems, regions and technologies most likely to advance SI given endowments of climate, soil and water resources.

\section{Global food security on a razor's edge}

After years of relatively stable and declining prices for the world's major staple food crops, the new millennium has brought considerably more turmoil in commodity markets. Since year 2000 there have been three episodes of abrupt spikes in prices of major staple grains compared to much greater price stability during the preceding two decades (Fig. 1). In each case relatively small deficits in global food supply attributed to drought, heatwave, flooding, or a combination of these stresses in one or more countries caused international commodity prices to increase by $50 \%$ or more. Accompanying these price spikes were episodes of political unrest in countries dependent on imports $^{6,7}$. Although export restrictions imposed by a few countries in response to production shortfalls and expanded biofuel mandates 


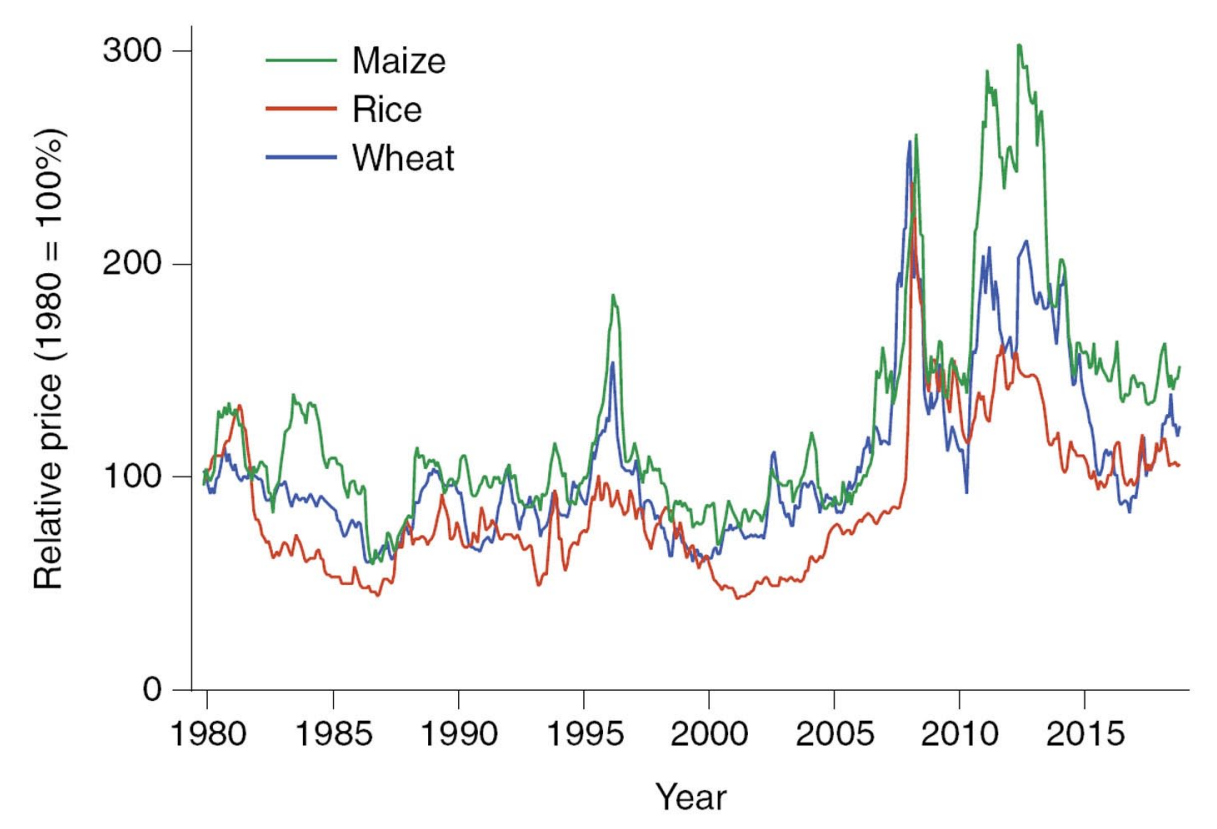

Fig. 1 Price trends of the major cereals from 1980-2018. Data source: World Bank international monthly price data ${ }^{52}$, under a Creative Commons License CC BY 4.0.

helped amplify these price spikes, in each case the triggering event was a grain production shortfall representing a relatively small share of global grain production.

In addition to vicious price spikes, other evidence of a tenuous global food supply includes rapid increase in land used for crop production and abrupt slowing, and sometimes complete stagnation, in the rate of yield increase on existing farmland ${ }^{8}$. For example, from 2002-2014, which includes the most recent available data, expansion of harvested crop production area increased at the fastest rate in human history (Fig. 2). The staple crops included in this analysis provide more than $75 \%$ of all calories in human diets, either directly consumed or as fed to livestock and fish for human consumption. Of these, maize, rice, wheat and soybean are the most widely grown and are responsible for about $70 \%$ of the increase in crop area since 2002, and most of the increase is due to conversion of natural ecosystems to farmland.

The fact that so much of this increase comes from production of just four crops attests to powerful demographic forces associated with economic development in the world's most populous countries of Asia, 


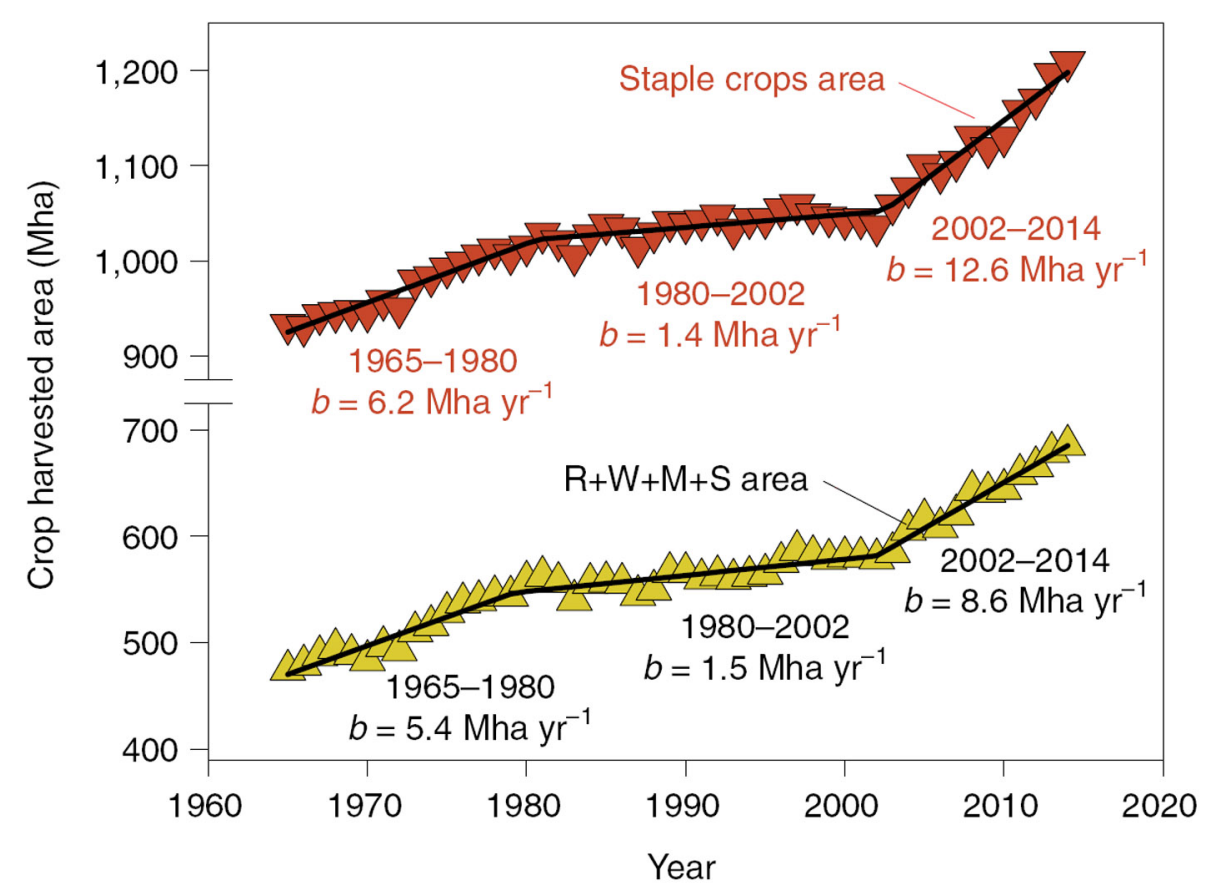

Fig. 2 Trends in global harvested area of the major staple food crops and of the four most widely grown crops. Data for the major stable food crops are shown as red triangles and data for the four most widely grown crops (rice (R), wheat (W), maize (M) and soybean (S)) are shown as yellow triangles. Regression coefficients were obtained from piecewise, linear regressions updated from Grassini et al. ${ }^{8}$. Staple crops include all major cereal, oil, sugar, pulse, sugar, fibre, tuber and root crops. Figure adapted with permission from ref ${ }^{8}$, Springer Nature Limited, under a Creative Commons License CC BY 3.o.

Africa and South America. Rising incomes leads to greater consumption of livestock products and higher per capita grain consumption, much of which is used for livestock production. And these trends are not likely to change over the next 30 years as billions more join the ranks of the global middle class and can afford a more diverse dietary fare that includes meat and dairy. Hence the call for reducing meat consumption as a means to lower agriculture's contribution to climate change ${ }^{9,10}$ is not relevant to those of low and modest incomes who currently eat very little meat ${ }^{11}$, and who represent the vast majority of new mouths to feed at the global dinner table in 2050.

Although global average yields of major food crops are still increasing at linear rates, relative growth rates are decreasing due to the tyranny of linear increase, which gives declining relative rates 
as average yields rise (Fig. 3a), and slowing or plateauing yields in many of the world's major breadbaskets (Fig. 3b). Examples of yield growth stagnation include wheat in northern Europe (accounting for $20 \%$ of global production) and rice in California (USA), while considerable slowing can be seen in yield trends of rice in China (accounting for 30\% of global production). In each case, slowing yield growth occurs in countries with highest yields due to diminishing returns on investments in yield-enhancing inputs and technologies as average farm yields approach biophysical limits on yield potential determined by climate, soil and water supply ${ }^{12}$. If yield growth follows current trajectories, projected food demand will not be met without large expansion of crop area, continuing or even accelerating the trends seen in Fig. 2.

Taken together, abrupt spikes in prices of major food crops associated with small temporary decreases in global production, and explosive expansion of crop production area are symptoms of a global food supply on a razor's edge of sufficiency. Hence the urgency to achieve rapid SI of agriculture in general, and of staple food crop production in particular, in tandem with appropriate policies and institutions to support it.

\section{Current global SI research portfolio}

The most visible published science on SI, as quantified by citation activity on Google Scholar under the term 'sustainable intensification' (https://scholar.google.com/), is centred on four main thrusts. The first calls for an expanded SI scope to include "adopting practices along the entire value chain of the global food system that meet rising needs for nutritious and healthy food through practices that build social-ecological resilience and enhance natural capital within the safe operating space of the Earth system" ${ }^{\prime 3}$. Additional SI-relevant

Fig. 3 Yield trends of major food crops. a, Global yield trends of major food crops: maize, rice, wheat, and soybean. Inset shows relative yield gains, calculated as the ratio of linear rate of yield gain and trend-line yield in a given year. $\mathbf{b}$, Yield trends in regions with slowing yield growth (rice in China) or yield plateaus (rice in California, USA, and wheat in northern Europe). Piecewise linear regression was used to obtain best fit to the data following Grassini et al. ${ }^{8}$. 

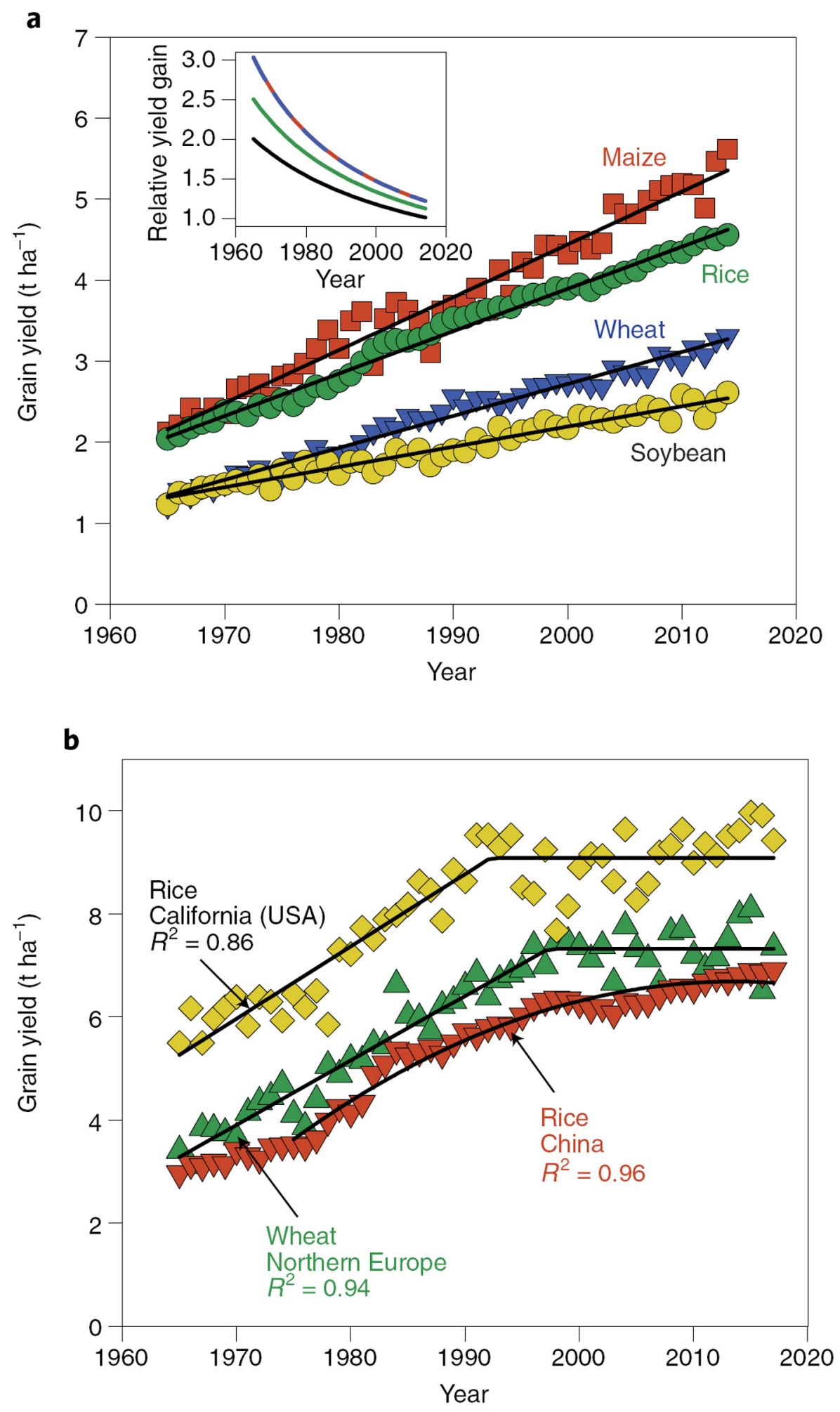
objectives have been proposed including animal welfare, viability of rural communities, sustainable development, adequate and equitable access to food, and food sovereignty ${ }^{5,14}$. These extensive views seek eradication of hunger and improved human nutrition, as well as environmental performance defined within concepts of safe operating space, multi-functional landscapes, performance goals of net zero GHG emissions, very low or zero expansion of agriculture into remaining natural ecosystems, zero loss of biodiversity, drastic reduction in excessive use of $\mathrm{N}$ and $\mathrm{P}$, major improvement in water productivity, and safeguarding of environmental water flows and groundwater quality. Addressing these multiple SI dimensions requires research that robustly links environmental performance at the level of a single production field or farm, with aggregated impact from thousands of fields and farms on non-agricultural ecosystems such as rivers, lakes, estuaries and coastal biomes. While general guidelines on planetary boundaries are suggested ${ }^{12}$, specific thresholds for individual farms and cropping systems remain poorly defined. Also required is a capacity to link biophysical SI performance in terms of increased food production and environmental stewardship to social benefits such as improved human health, poverty reduction and integrity of rural communities ${ }^{15}$.

A second thrust focuses on improving crops and cropping systems in low-income developing countries of Sub-Saharan Africa and Asia where current yield gaps are large. And while sustainable intensification is relevant to these regions, the scientific challenge is muted by the fact that existing production systems are very low yielding because they receive few inputs of fertilizers, improved seed and pest control measures, and thus have undergone very little intensification $^{11}$. In many cases the major constraint is soil degradation caused by inadequate nutrient inputs and little return of crop residues to maintain soil organic matter ${ }^{16}$. Hence it is possible to achieve substantial progress towards SI with little danger of negative environmental impact through use of existing technologies such as judicious use of fertilizer and improved crop cultivars with greater resistances to drought and pests. Gaining widespread use of these inputs requires policies, markets and infrastructure that support adoption by smallholder farmers ${ }^{17}$. At some point, however, gains from this approach reach a level at which more aggressive intensification is required to sustain yield gains, such as use of greater amounts of fertilizer inputs 
and proactive pest management tactics to control insect pests, weeds and diseases. At this point, the challenge of dealing with planetary boundaries comes into play, including more radical changes in the cropping systems themselves.

A third, and growing, body of SI literature calls for a shift to greater diversity of crops and cropping systems as a means to improve human nutrition through production of more nutritious crop species than the primary cereals, and because greater crop diversity can sometimes reduce risk, improve soil health and reduce need for fertilizer and pesticides $^{18,19}$. While such work may be relevant for specific situations and local conditions, its global relevance can be questioned because it fails to recognize the reasons why the current human food supply relies so heavily on a small number of crops, and the fact that much of the developing world depends on grain imports to meet basic food needs. Indeed, our globalized food system is tuned to the inherent characteristics of the major cereal and oilseed crops because they are easily dried and stored for long periods of time, easily transported over long distances, and have low energy requirements for processing and cooking when used directly as human food (especially for maize, rice and wheat). Low energy requirements for processing and cooking represent an important quality-of-life benefit for low-income families who rely on daily collection of firewood for cooking fuel. In addition, these four major crops produce higher yields of calories, protein and oil per unit time, light, water and nutrient inputs than most other crop species. And as previously mentioned, rapid economic growth in the world's most populous developing countries supports rising income, which in turn is highly correlated with per capita consumption of meat, dairy and fish. Rapid increase in demand for these foods cannot be met by traditional, small-scale livestock production systems, so large-scale livestock feeding operations fill the gap and require enormous amounts of feed grains and high-protein seed meal. While less intensive, lower yielding, more diverse production systems may offer local environmental benefits, there are trade-offs if widely adopted due to indirect effects of land clearing elsewhere to meet food demand in global markets ${ }^{5,11}$.

A fourth thrust includes work that seeks to establish metrics that measure progress towards SI at the field or farm level ${ }^{19-23}$. Most studies of this kind focus on metrics associated with input-use efficiencies for fertilizers, energy, and water due to lack of well-defined 
environmental performance thresholds. In addition to these yield and efficiency metrics, a recent study of maize systems in Malawi included risk of crop failure, probability of food sufficiency, and ratings of crop and soil management options by women, all of which are important considerations for smallholder farms in most countries of Sub-Saharan Africa ${ }^{24}$.

\section{No time to waste in research prioritization}

The combined impact of slowing yield growth in the world's major breadbaskets and rapid expansion of crop production area puts our global food system on an unsustainable path. Whereas only $13 \%$ of the increase in global production of soybean, maize, rice and wheat came from expansion of harvested area from 1980-2002, area expansion contributed most of the increase from 2002-2014 (Fig. 4). These trends are clearly not consistent with SI goals and suggest an urgency

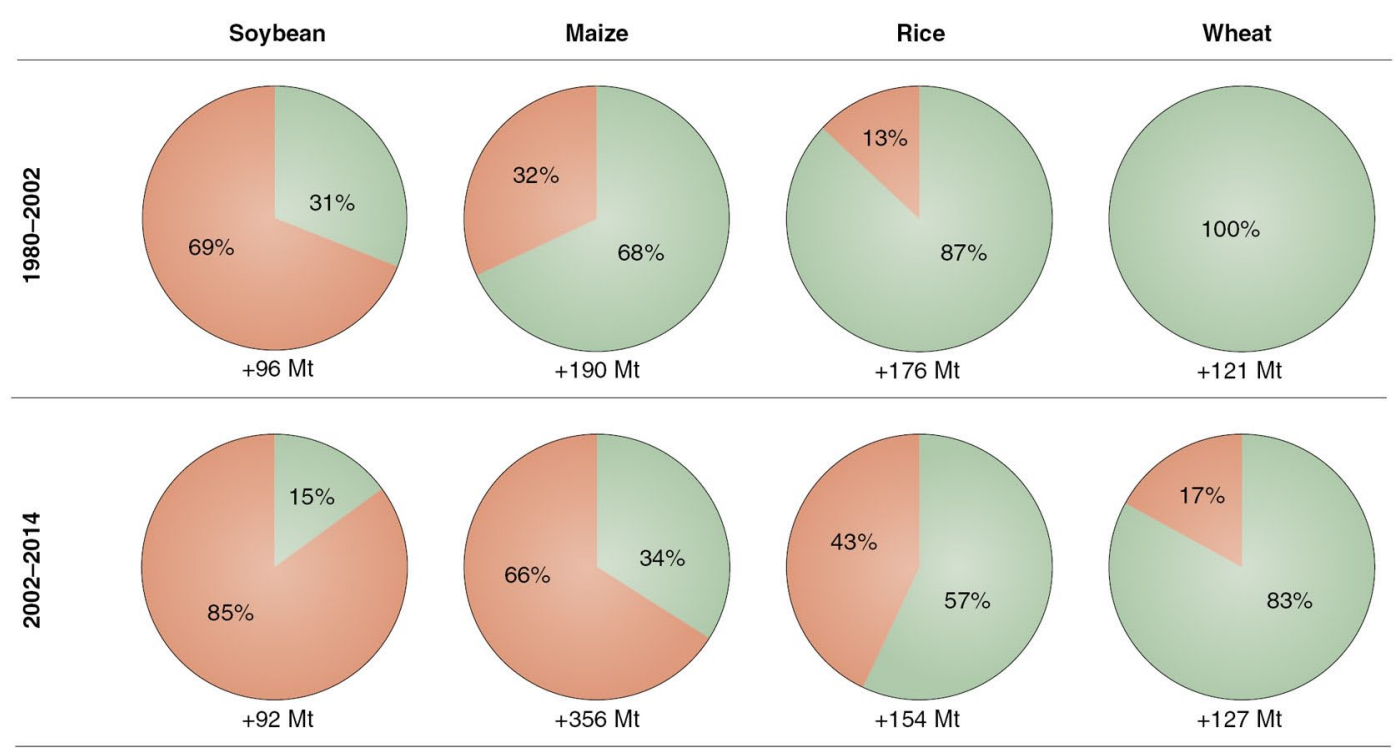

Fig. 4 Contributions to global supply of major food crops from yield gain on existing crop land (green) or expansion of harvested crop production area (brown) in two periods. Increases in production, area and yield are based on 3-year averages centred on initial and final years for each period. We assume yield levels of new crop area in a given period are the same as yields on existing crop land, which may overestimate contributions from crop area expansion. Mt, million metric tons. Data from ref. 53 . 
in the quest to achieve SI at a scale that can have global impact. At issue is whether the current global R\&D portfolio is up to the task and how to monitor progress. The answer depends on assumptions about the time frame, magnitude of food demand increase that is needed, and required improvements in environmental performance. The time frame in which solutions are needed has a large influence on research prioritization because the time required to develop new technologies and farming approaches differs depending on the type of research undertaken. We suggest a time frame consistent with the demographic transition to a global population growth rate approaching zero, which is projected to occur by mid-century, 30 years from now.

The magnitude of increase in food supply and the types of food that comprise human diets determine the crops and cropping systems that will be needed. The most likely scenario is a food demand increase that follows historical trajectories in income growth and diets, and the relationship between the two. Tilman et al. ${ }^{11}$ use a robust approach to estimate food demand under this 'business as usual' scenario, which represents a $1.55 \%$ annual rate of increase. This rate is well above current yield growth rates of about 1.0-1.2\% for the major food crops (Fig. 3b). Assuming a more conservative 50\% increase in food demand over the next 30 years from 2020 to 2050 means that yields of the major food crops must accelerate by about 30\% from current levels to meet demand on existing farmland. The magnitude of acceleration, however, can be reduced through expanded use of cropping systems that produce more than one crop per year on the same field to give a substantial increase in total production without a yield increase per $\mathrm{se}^{25,26}$.

Given a 30-year time frame, 'quantum leap' innovations in genetic improvement and development of new crops and cropping systems are unlikely to have a large impact on SI over this period. For example, breakthroughs from genetic modifications to give large improvements in complex traits like photosynthesis, nitrogen- use efficiency and drought resistance require decades of work underpinned by large commitments of financial resources and success is highly uncertain ${ }^{27}$. Recent examples of large investments by the private sector in a transgenic solution to drought resistance documents the high risk inherent to this approach ${ }^{28}$. And while transgenic crops will play an important role to improve crop disease and insect resistances and nutritional quality, genetic engineering will not likely produce quantum-leap 
technologies for increasing complex traits like yield potential, nitrogen-use efficiency and drought resistance because these traits are controlled by a large number of genes with trade-off penalties associated with only optimizing a few of them. Fine-tuned manipulation of multiple genes that control intricate biochemical and physiological processes is currently beyond capabilities of genetic engineering. Similarly, development of new crops and cropping systems that achieve widespread adoption at a globally relevant scale is a long-term proposition. Indeed, there have been no globally important new crops or cropping systems developed in the past 40 years since the introduction of double-crop rice and rice-wheat cropping systems made possible by the early maturity 'miracle' rice and wheat cultivars that initiated the green revolution in the 196os, or introduction of soybean to the Brazilian Cerrados in the 1970s.

Although quantum leaps are unlikely, we can expect continued incremental yield gains from genetic improvements in resistance to abiotic and biotic stresses and fine-tuning crop maturities to fit changing climate using brute-force breeding programs guided by precision phenotyping, genomics and genetic prediction methodologies linked to robust crop simulation models ${ }^{29}$. Likewise, further intensification through production of more than one crop per year on the same field to give substantially higher total annual yield is made possible by adoption of shorter-maturing cultivars and mechanized tillage and harvesting operations in systems that are currently labour intensive, which includes most low-income developing countries. Longer growing seasons from warmer temperatures under climate change and high-speed precision planters promise considerable expansion of double-cropping in large-scale mechanized systems where rainfall or irrigation provides sufficient water supply for an additional crop. In cool temperate climates, earlier sowing dates permitted by warming temperatures give incrementally higher yields due to longer growing seasons coupled with the use of crop cultivars with later maturity $^{30,31}$. 'Orphan' crops such as cassava, sweet potato, sorghum, millet, and some grain legumes with large yield potential and efficient use of water and nutrients may have potential for contributing to SI at national and global scales if there is demand for such crops in the marketplace and processing, storage and shipping technologies are available to minimize waste and spoilage. 
In addition to an acceleration in total food production on existing farmland, a large reduction in negative environmental impacts is also needed. The most appropriate research agenda to address this challenge depends in large part on the types of negative environmental externalities addressed and the magnitude of reduction required. Here we propose a 50\% target for improvements in water, nitrogen, and energy-use efficiencies coupled with a similar magnitude of reduction in soil erosion and GHG emissions. Although negative impacts from agriculture ultimately must fall below critical environmental thresholds based on robust water quality, emissions and biodiversity standards yet to be determined, the proposed 50\% reduction provides a reasonable initial target for research prioritization purposes. It is notable, for example, that a 50\% decrease is consistent with estimates of the $\mathrm{N}$ load reduction required to address the hypoxia problem in the Gulf of Mexico due to $\mathrm{N}$ losses from agriculture in the US Mississippi River watershed ${ }^{32}$. Promising component technologies to improve environmental performance include smart fertilizers that provide adequate nutrient supply with minimal environmental losses, cover crops that recover nutrients at risk of loss and improve soil quality, robotic pest control that replaces chemical biocides, strategically placed buffer strips and biofilters that remove pollutants from runoff, and continued increases in adoption of conservation tillage that maintains soil coverage and reduces erosion.

Although SI goals are relevant across spatial scales and cropping systems, the means are not. Hence effective R\&D prioritization requires identification of specific systems, crops and geographies with greatest potential to contribute to SI goals. A scenario that requires a $50 \%$ increase in food supply by 2050 reduces the degrees of freedom in terms of crops and cropping systems to be considered because establishing new crops and cropping systems is not likely to occur at scale within the next 30 years. Hence, we would argue that major emphasis should be placed on SI of the crops currently in greatest demand and which are responsible for most of the global expansion in crop production area. On the other hand, a survey of food security researchers suggests it might be possible to reduce food demand increase through decreased consumption of livestock products in highincome countries, reduced food losses and waste along the food chain from farm to consumer, and reduced use of human-edible foods for 
biofuel production ${ }^{3}$. Under a scenario in which food demand increase to 2050 is halved, from $50 \%$ to only $25 \%$, the current annual rate of gain in crop yields of $1-1.2 \%$, as shown in the insert of Fig. 3a, is roughly adequate to meet 2050 demand without a large expansion of crop production area. Likewise, this slower food demand growth scenario allows greater degrees of freedom in the types of crops and cropping systems to meet that demand.

Once priority crops and cropping systems have been identified, selection of regions with greatest potential for contributing to SI becomes an issue. Yield gap analysis that quantifies the difference between current average farm yields and yield potential provides insight about where greatest gains in yield are possible on existing cropland, and the reliability of those yields due to variability in weather ${ }^{34}$. Yield gap assessments intended to inform research prioritization require adequate spatial resolution and agronomic relevance, which in turn depend on a robust 'bottom-up' spatial aggregation approach and location-specific data on soils, climate and cropping systems ${ }^{35-37}$. Assessments based on 'top-down', gridded spatial frameworks without location-specific agronomic detail are not reliable for research prioritization purposes at regional or national scales ${ }^{38}$.

\section{Gaps in the global research portfolio}

There is a strong scientific consensus on three points. First, that meeting food demand for approximately 10 billion by mid-century 39 in a sustainable fashion is one of humanity's greatest challenges. Climate change further augments the magnitude of this challenge. Second, that SI is the path to meeting that challenge because it minimizes the pressure for further conversion of natural ecosystems to farmland. Third, that yield, the nutritional value of that yield, and environmental performance metrics are the yardsticks by which SI is measured rather than by the farming approaches or types of inputs used to achieve them. Given this remarkable degree of agreement, the lack of vigorous discussion about scope and focus of national and global SI research portfolios is peculiar, especially because we are well behind the curve in terms of achieving production increases on existing farmland and reducing negative environmental impacts. As a means to promote this dialogue, we have attempted to characterize the major foci 
of the current global SI research portfolio and the factors with greatest influence on research prioritization. Here we attempt to identify gaps in that portfolio that need filling.

Effective research prioritization is like betting on horses at the racetrack to increase chances of selecting winners. Largest bets are made on horses with best odds of winning, and smaller bets on horses with poorer odds, where the 'odds' represent a composite rating determined by cost of performing the research, probability of success, time frame to produce technologies ready for widespread adoption by farmers, and the scale of potential impact. The 'odds' are also tempered by assumptions about magnitude of expected food demand increase and environmental standards. Because several of these composite rating factors are somewhat subjective and rely to a large extent on expert opinion, it is wise to spread out investments on more than a single horse with highest odds.

As we see it, the most likely scenario is that the global food system in 2050 becomes increasingly globalized and trade-dependent due to the demographic weight of urbanization, which is expected to rise from $55 \%$ of global population today to nearly $70 \%$ by $2050^{40}$. Therefore we see the 'business as usual' scenario as the odds-on favourite by a large margin, which means greatest emphasis on: (1) accelerating SI of current major crops and cropping systems in the world's most important breadbaskets; (2) regions with large upside potential due to endowments of favourable climate and good soils that support high and stable yields as can now be identified by yield gap analysis ${ }^{37,41}$; and (3) expansion of irrigated agriculture in regions with sufficient renewable water supply to support it, such as some regions of SubSaharan Africa ${ }^{2,43}$ and South America.

Although there is considerable investment in component technologies to support SI of current major crops and cropping systems, especially in the private sector, there is little research on putting the components together in viable production systems, and in quantifying SI potential in terms of both production and environmental performance in farmers' fields rather than small manicured research plots. Such systems-level research would include assessing environmental impacts at landscape and watershed scales, which represents a critical missing link in the current global portfolio. Also missing are robust metrics to monitor environmental performance that simplify on the far side of complexity. The nitrogen balance metric, which represents 
the difference between nitrogen inputs and removal from a production field or farm, is an example of such a metric ${ }^{44}$. Water productivity, quantified by the amount of grain produced per unit of water supply, is another ${ }^{45,46}$. Robust and parsimonious metrics for monitoring biodiversity and soil health, and the scale at which to measure them, remain elusive.

New agronomic research methods are needed to accelerate innovation in identification of best management practices for a given crop, soil and climate combination ${ }^{47}$. Traditional replicated field experiments using standard statistical designs are not up to the task because they have trouble evaluating more than two or three factors at once. In contrast, farmers must fine-tune and optimize 10-20 crop and soil management factors to achieve yields that approach yield potential $^{12}$, and the manner in which one factor is implemented influences the outcome from each of the other factors. Here the term 'management factors' is used in the broad sense to include crop rotation, cover crops, tillage method, seed treatments, sowing dates, plant population, weed control measures, fertilizer application rates, timing, placement and formulation for all essential nutrients, use of manure or compost, insect and disease control measures, and in irrigated systems-irrigation method, amounts and timing. Moreover, management options and optimal combinations of practices change rapidly as new technologies come to market. Farmer-reported data on management practices used in their fields and associated Global Positioning System (GPS) coordinates make it possible to deal with this complexity by classifying each production field into a cohort group with sufficient similarity in soil type and climate that a given management practice, or combination of practices, would be expected to perform similarly across all fields in that category. Use of straightforward statistics can then identify the combination of practices that perform best across a given cohort group of fields, which overcomes the constraints of traditional agronomic research because each farmer's field represents an 'experiment'. For example, optimal management practices can be identified by the practices used in fields that achieve highest yields for a given climate and soil cohort group (for example, the top 10\% highest yielding fields), and the statistical power of identifying these combinations is greatly increased because cohort groups often contain many thousands of fields ${ }^{48,49}$. Farmer concerns about privacy and not sharing in 
the value obtained from their data could be overcome by establishing farmer-controlled 'data cooperatives' whereby those who contribute data receive an annual report benchmarking performance of each of their fields versus all other fields in the same soil and climate cohort group, as well as the suite of management practices used in fields that achieve highest yields, input-use efficiencies, and associated environmental performance metrics.

Although achieving SI to ensure global food security by 2050 is a massive scientific challenge, it is not beyond reach if there are wellprioritized national and global R\&D agendas with a ruthless focus on the dual objectives of achieving large increases in yields on existing farmland coupled with substantial improvement in environmental performance that adequately protects natural resources, environmental services and minimizes GHG emissions. A 50\% yield increase on existing farmland in tandem with a 50\% decrease in negative environmental externalities provide useful initial targets for establishing national SI research portfolios. The required science must come from a wide array of disciplines including basic and applied sciences that extend well beyond traditional agricultural sciences to embrace computer and computational sciences (including 'big data' analytics), landscape ecology, and molecular biology to name a few. But achieving the required degree of SI in national and global food production systems is only one piece of the food security challenge; it must be complemented by social, political and economic conditions that ensure access, affordability and adequate nutrition for all. While $\mathrm{R} \& \mathrm{D}$ on the biophysical attributes of SI is necessary, it is not sufficient because there is critical need for appropriate policies, institutions and trade agreements to ensure that successful SI in terms of production and environmental goals leads to land sparing for nature and an affordable and nutritious food supply for all5,50,51. Regardless of scope and scale, one thing is clear: without SI in the strict sense of increasing crop yields on existing farmland while substantially reducing negative environmental impacts, it will be difficult to achieve a food-secure world without considerable loss of biodiversity and accelerated climate change. Hence the importance of adequate investment and effective R\&D prioritization to reach the required degree of SI in food production systems that contribute most to human food supply. 
Author contributions - The subject-matter outline of the Perspective was developed by K.G.C. and figures were prepared by P.G. Writing and editing were performed by K.G.C. and P.G.

Competing interests - The authors declare no competing interests.

\section{References}

1. Pretty, J. \& Bharucha, Z. P. Sustainable intensification in agricultural systems. Ann. Bot. 114, 1571-1596 (2014).

2. Cassman, K. G. Ecological intensification of cereal production systems: yield potential, soil quality, and precision agriculture. Proc. Natl Acad. Sci. USA 96, 5952-5959 (1999).

3. Godfray, H. C. J. \& Garnett, T. Food security and sustainable intensification. Phil. Trans. R. Soc. B 369, 20120273 (2014).

4. Pretty, J. The sustainable intensification of agriculture. Nat. Resour. Forum 21, 247-256 (1997).

5. Garnett, T. et al. Sustainable intensification in agriculture: premises and policies. Science 341, 33-34 (2013).

6. Lagi, M., Bertrand, K. Z. \& Bar-Yam, Y. The Food Crises and Political Instability in North Africa and the Middle East (SSRN, 2011).

7. Barrett, C. B. in Food Security and Sociopolitical Stability (ed. Barrett, C. B.) 1-34 (Oxford Univ. Press, 2013).

8. Grassini, P., Eskridge, K. M. \& Cassman, K. G. Distinguishing between yield advances and yield plateaus in historical crop yield trends. Nat. Commun. 4, 2918 (2013).

9. Bajželj, B. et al. Importance of food-demand management for climate mitigation. Nat. Clim. Change 4, 924-929 (2014).

10. Stehfest, E. et al. Climate benefits of changing diet. Clim. Change 95, 83-102 (2009).

11. Tilman, D., Balzer, C., Hill, J. \& Befort, B. L. Global food demand and sustainable intensification of agriculture. Proc. Natl Acad. Sci. USA 108, 20260-20264 (2011).

12. Cassman, K. G., Dobermann, A., Walters, D. T. \& Yang, H. Meeting cereal demand while protecting natural resources and improving environmental quality. Annu. Rev. Environ. Resour. 28, 315-358 (2003).

13. Rockström, J. et al. Sustainable intensification of agriculture for human prosperity and global sustainability. Ambio 46, 4-17 (2017).

14. Loos, J. et al. Putting meaning back into "sustainable intensification". Front. Ecol. Environ. 12, 356-361 (2014).

15. Andrade, J. F. et al. A spatial framework for ex-ante impact assessment of agricultural technologies. Glob. Food Secur. 20, 72-81 (2019). 
16. Tittonell, P. \& Giller, K. E. When yield gaps are poverty traps: the paradigm of ecological intensification in African smallholder agriculture. Field Crops Res. 143, 76-90 (2013).

17. Vanlauwe, B. et al. Sustainable intensification and the African smallholder farmer. Environ. Sustain. 8, 15-22 (2014).

18. Pretty, J. et al. Global assessment of agricultural system redesign for sustainable intensification. Nat. Sustain. 1, 441-446 (2018).

19. Mabhaudhi, T. et al. Mainstreaming underutilized indigenous and traditional crops into food systems: a South African perspective. Sustainability 11, 172 (2019).

20. Barnes, A. P. \& Thompson, S. T. Measuring progress towards sustainable intensification: how far can secondary data go? Ecol. Indic. 36, 213-220 (2014).

21. Gadanakis, Y., Bennett, R., Park, J. \& Areal, F. J. Evaluating the sustainable intensification of arable farms. J. Environ. Manag. 150, 288-298 (2015).

22. Smith, A. et al. Measuring sustainable intensification in smallholder agroecosystems: a review. Glob. Food Secur. 12, 127-138 (2017).

23. Thomson, A. M. et al. Science in the supply chain: collaboration opportunities for advancing sustainable agriculture. Agric. Environ. Lett. 2, 170015 (2017).

24. Snapp, S. S. et al. Maize yield and profitability tradeoffs with social, human and environmental performance: is sustainable intensification feasible? Agric. Syst. 162, 77-88 (2018).

25. Andrade, J. F., Poggio, S. L., Ermacora, M. \& Satorre, E. H. Land use intensification in the Rolling Pampa, Argentina: diversifying crop sequences to increase grain yields and resource use. Eur. J. Agron. 82, 1-10 (2017).

26. Guilpart, N., Grassini, P., Sadras, V. O., Timsina, J. \& Cassman, K. G. Estimating yield gaps at the cropping system level. Field Crops Res. 206, 21-32 (2017).

27. Hall, A. J. \& Richards, R. Prognosis for genetic improvement of yield potential and water-limited yield of major grain crops. Field Crops Res. 143, 18-33 (2013).

28. Cassman, K. G. Long-Term Trajectories: Crop Yields, Farmland, and Irrigated Agriculture 21-46 (Federal Reserve Bank of Kansas City Economic Review, Special Issue, 2016).

29. Cooper, M., Gho, C., Leafgren, R., Tang, T. \& Messina, C. Breeding droughttolerant maize hybrids for the US corn-belt: discovery to product. J. Exp. Bot. 65, 6191-204 (2014).

30. Kucharik, C. J. Contribution of planting date trends to increased maize yields in the central United States. Agron. J. 100, 328-336 (2008).

31. Sacks, W. J. \& Kucharik, C. J. Crop management and phenology trends in the U.S. Corn Belt: impacts on yields, evapotranspiration and energy balance. Agric. For. Meteorol. 151, 882-894 (2011).

32. McLellan, E. et al. Reducing nitrogen export from the Corn Belt to the Gulf of Mexico: agricultural strategies for remediating hypoxia. J. Am. Water Resour. Assoc. 51, 263-289 (2015). 
33. Keating, B. A., Herrero, M., Carberry, P. S., Gardner, J. \& Cole, M. B. Food wedges: framing the global food demand and supply challenge towards 2050 . Glob. Food Secur. 3, 125-132 (2014).

34. van Ittersum, M. K. et al. Yield gap analysis with local to global relevance - a review. Field Crops Res. 143, 4-17 (2013).

35. Grassini, P. et al. How good is good enough? Data requirements for reliable crop yield simulations and yield-gap analysis. Field Crops Res. 177, 49-63 (2015).

36. van Bussel, L. G. J. et al. From field to atlas: upscaling of location-specific yield gap estimates. Field Crops Res. 177, 98-108 (2015).

37. van Ittersum, M. K. et al. Can Sub-Saharan Africa feed itself? Proc. Natl. Acad. Sci. USA 113, 14964-14969 (2016).

38. Deng, N. et al. Closing yield gaps for rice self-sufficiency in China. Nat. Commun. 10, 1725 (2019).

39. World Population Prospects (United Nations Division of Economics and Social Affairs, 2019).

40. The 2018 Revision of the World Urbanization Prospects (United Nations Division of Economics and Social Affairs, 2018).

41. Guilpart, N. et al. Rooting for food security in Sub-Saharan Africa. Environ. Res. Lett. 12, 114036 (2017).

42. MacDonald, A. M., Bonsor, H. C., Dochartaigh, B. É. Ó. \& Taylor, R. G. Quantitative maps of groundwater resources in Africa. Environ. Res. Lett. 7, 021003 (2012).

43. Cassman, K. G. \& Grassini, P. Can there be a green revolution in Sub- Saharan Africa without large expansion of irrigated crop production? Glob. Food Secur. 2, 203-209 (2013).

44. McLellan, E. L. et al. The nitrogen balancing act: tracking the environmental performance of food production. BioScience 68, 194-203 (2018).

45. Passioura, J. Increasing crop productivity when water is scarce-from breeding to field management. Agric. Water Manage. 8o, 176-196 (2006).

46. Grassini, P. et al. High-yield irrigated maize in the Western U.S. Corn Belt: II. Irrigation management and crop water productivity. Field Crops Res. 120, 133-144 (2011).

47. Rattalino Edreira, J. I. et al. Beyond the plot: technology extrapolation domains for scaling out agronomic science. Environ. Res. Lett. 13, 054027 (2018).

48. Rattalino Edreira, J. I. et al. Assessing causes of yield gaps in agricultural areas with diversity in climate and soils. Agric. For. Meteorol. 247, 170-180 (2018).

49. Mourtzinis, S. et al. Sifting and winnowing: analysis of farmer field data for soybean in the US North-Central region. Field Crops Res. 221, 130-141 (2018).

50. Byerlee, D., Stevenson, J. \& Villoria, N. Does intensification slow crop land expansion or encourage deforestation? Glob. Food Secur. 3, 92-98 (2014). 
51. Phalan, B. How can higher-yield farming help to spare nature? Science 351, 450-451 (2016).

52. Commodity Markets (World Bank); https://go.nature.com/39QAzJQ

53. FAOSTAT: Crops (FAO); http://www.fao.org/faostat/en/\#data/QC 